\title{
Deformation of the Augustine Volcano, Alaska, 1992-2005, measured by ERS and ENVISAT SAR interferometry
}

\author{
Chang-Wook Lee ${ }^{1,3}$, Zhong Lu², Oh-Ig Kwoun ${ }^{3}$, and Joong-Sun Won ${ }^{1}$ \\ ${ }^{1}$ Department of Earth System Sciences, Yonsei University, 134 Sinchon-dong, Seodaemun-gu, Seoul 120-749, Korea \\ ${ }^{2}$ U.S. Geological Survey, U.S.A. \\ ${ }^{3}$ SAIC, U.S. Geological Survey Center for Earth Resources Observation and Science, Sioux Falls, SD, U.S.A.
}

(Received October 14, 2006; Revised March 12, 2007; Accepted September 7, 2007; Online published May 16, 2008)

\begin{abstract}
The Augustine Volcano is a conical-shaped, active stratovolcano located on an island of the same name in Cook Inlet, about $290 \mathrm{~km}$ southwest of Anchorage, Alaska. Augustine has experienced seven significant explosive eruptions - in 1812, 1883, 1908, 1935, 1963, 1976, 1986, and in January 2006. To measure the ground surface deformation of the Augustine Volcano before the 2006 eruption, we applied satellite radar interferometry using Synthetic Aperture Radar (SAR) images from three descending and three ascending satellite tracks acquired by European Remote Sensing Satellite (ERS) 1 and 2 and the Environment Satellite (ENVISAT). Multiple interferograms were stacked to reduce artifacts caused by atmospheric conditions, and we used a singular value decomposition method to retrieve the temporal deformation history from several points on the island. Interferograms during 1992 and 2005 show a subsidence of about 1-3 cm/year, caused by the contraction of pyroclastic flow deposits from the 1986 eruption. Subsidence has decreased exponentially with time. Multiple interferograms between 1992 and 2005 show no significant inflation around the volcano before the 2006 eruption. The lack of a pre-eruption deformation signal suggests that the deformation signal from 1992 to August 2005 must have been very small and may have been obscured by atmospheric delay artifacts.
\end{abstract}

Key words: Surface deformation, atmospheric effects, interferograms, pyroclastic flow deposits, subsidence.

\section{Introduction}

The "eruption cycle" of a volcano can be conceptualized as a series of events from deep magma generation to surface eruption that include such stages as partial melting, initial ascent through the upper mantle and lower crust, crustal assimilation, magma mixing, degassing, shallow storage and, finally, ascent to the surface (Dzurisin, 2003). This process is complex and varies from one eruption to the next and from volcano to volcano. In many cases, volcanic eruptions are preceded by pronounced ground deformation in response to increasing pressure from magma chambers or the upward intrusion of magma (Dvorak and Dzurisin, 1997). Therefore, surface deformation patterns have the potential to shed important insights into the structure, plumbing, and state of restless volcanoes (Dvorak and Dzurisin, 1997; Dzurisin, 2003) and can be the first sign of increasing levels of volcanic activity, preceding swarms of earthquakes or other precursors that signal impending intrusions or eruptions. The ability to map surface deformation associated with volcanic events is the key to protecting public welfare as well as furthering scientific understanding of these dynamic processes.

Roughly $10 \%$ of the world's active volcanoes are located in Alaska. Although the frequency of eruptions in Alaska is high, particularly in the Aleutian arc, these volcanoes re-

Copyright (C) The Society of Geomagnetism and Earth, Planetary and Space Sciences (SGEPSS); The Seismological Society of Japan; The Volcanological Society of Japan; The Geodetic Society of Japan; The Japanese Society for Planetary Sciences; TERRAPUB main poorly studied due to their remote location. Surface change monitoring that consists of sparsely distributed continuous Global Positioning System (GPS) stations or sporadically occupied campaign GPS sites can be prohibitively expensive, logistically challenging, and often not adequate for characterizing the complex deformation patterns associated with hazardous volcanic processes. This limitation poses a significant problem for studying volcanoes in the region, and more cost-effective strategies are required to comprehensively monitor these and similar remote and poorly understood volcanoes.

Interferometric Synthetic Aperture Radar (InSAR) (e.g., Massonnet and Feigl, 1998; Rosen et al., 2000; Zebker et al., 2000) from space-based platforms can provide an important complementary capability for ground-based monitoring of surface deformation. InSAR images provide a synoptic view that encompasses the volcano and surrounding area. The successful application of InSAR to volcanoes has been demonstrated at numerous locations around the world, including sites in Alaska (e.g., Lu et al., 2003; Lu, 2007). In addition to volcano-wide deformation related to magma injection and eruption, InSAR has revealed local deformation associated with young lava and pyroclastic flows (Briole et al., 1997; Stevens et al., 2001; Lu et al., 2005). The deformation of erupted material can provide insights into the post-emplacement behavior of lava and pyroclastic flows and suggests the need for caution in the interpretation of volcano-wide deformation patterns at active volcanoes.

Augustine Volcano is a $1250-\mathrm{m}$-high and $90-\mathrm{km}^{2}$-size 

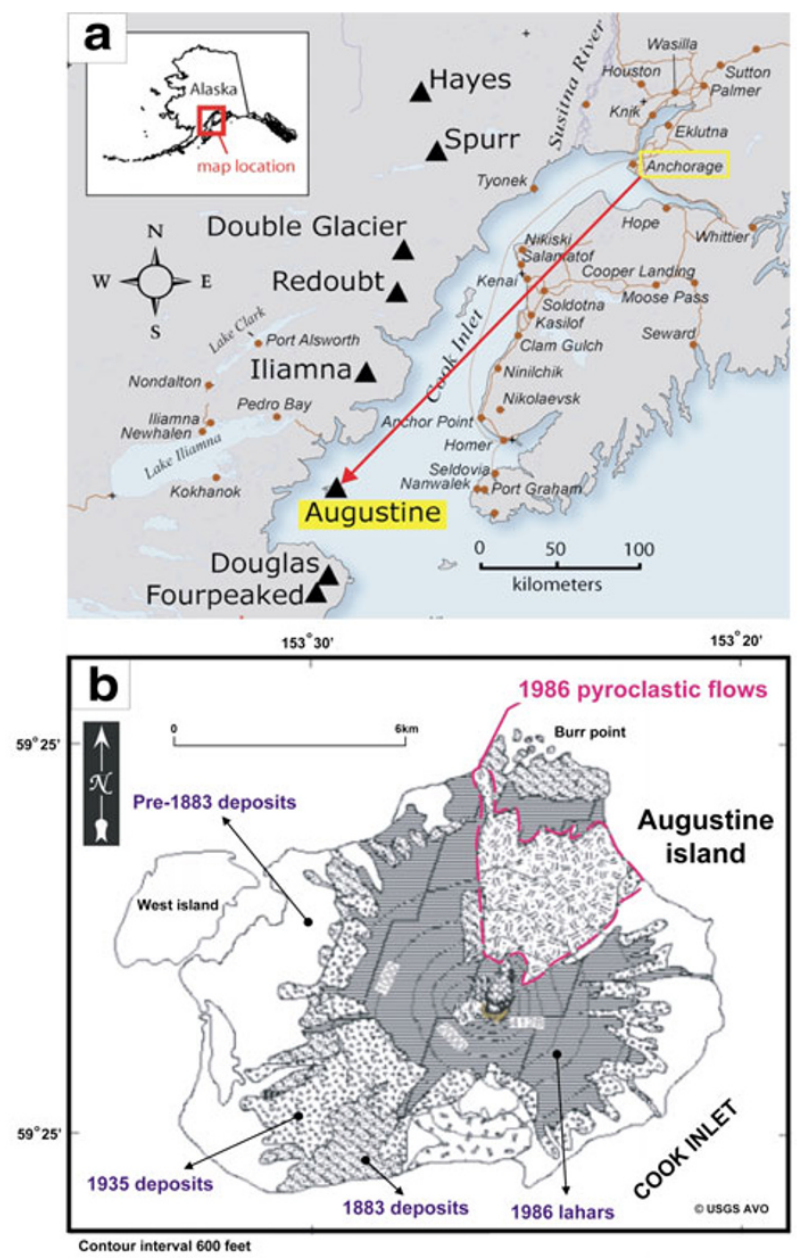

Fig. 1. (a) Augustine Island is located in the southwestern portion of the Cook Inlet, Alaska, about $290 \mathrm{~km}$ southwest of the city of Anchorage. (b) Geologic map showing the distribution of deposits of Augustine Volcano eruptions from the first documeted eruption in 1812 through to the 1986 eruption. Pyroclastic flow deposits emplaced in 1986 are located primarily in the north northeastern part of island.

island stratovolcano in southwestern Cook Inlet, about $290 \mathrm{~km}$ southwest of Anchorage, Alaska (Fig. 1). Augustine Island was formed on Jurassic and Cretaceous sedimentary strata and overlain by granitoid glacial erratics and volcanic hyaloclastites (Miller et al., 1998).

Augustine Volcano is one of the youngest and most active volcanoes in Cook Inlet (Begét and Kowalik, 2006), having experienced significant explosive eruptions in 1812, 1883, 1935, 1963, 1976, 1986 and, most recently, in 2006. The most violent of these eruptions was in 1883 , when a debris avalanche generated a small tsunami in Cook Inlet (Miller et al., 1998). Most eruptions of Augustine began with an initial series of vent-clearing explosions with pyroclastic flows, surges, and lahars on the volcano flanks, followed by the extrusion of andesitic lava from the volcano's summit (Waythomas and Waitt, 1998). Pyroclastic flows generated by the 1986 eruption covered a fan-shaped region on the north-northeast flank of the volcano with lithic-rich pumice deposits.

Preliminary results based on a limited number of InSAR images have indicated an active deformation of the north flank of Augustine Volcano between 1992 and 1999 (Lu et al., 2003). This region of deformation corresponds to the area covered by the 1986 pyroclastic flow deposits, and, accordingly, the subsidence has been attributed to the postemplacement behavior of the unit. Using an InSAR image of Augustine spanning 1992-1993, Masterlark et al. (2006) constructed finite element models that simulated the posteruptive thermoelastic contraction of the initially hot and geometrically complex 1986 pyroclastic flow deposits. By combining the 1992-1993 InSAR image, the finite element model, and an adaptive mesh algorithm to iteratively optimize the geometry of the deposit, Masterlark et al. (2006) determined an initial excess temperature for the pyroclastic flow unit of $640^{\circ} \mathrm{C}$ and an average thickness of $9.3 \mathrm{~m}$.

In this study, we systematically processed all of the available InSAR images for the Augustine Volcano between 1992 and 2005 using Synthetic Aperture Radar (SAR) images acquired by the European Remote sensing Satellite (ERS)-1, ERS-2, and the Environment Satellite (ENVISAT). Our goal was to investigate: (1) how the subsidence of the 1986 pyroclastic flow evolved between 1992 and 2005, and (2) whether or not volcano-wide deformation preceded the unrest and eruption of 2005-2006, as is expected based on InSAR observations from other Alaskan volcanoes (Lu et al., 2003; Lu, 2007).

\section{InSAR Observations and Analysis}

\subsection{SAR images and digital elevation model}

InSAR images used in this study (Table 1) consist of: (1) about 630 interferograms from five independent tracks of C-band (wavelength $=5.66 \mathrm{~cm}$ ) ERS- 1 and ERS-2 SAR images spanning the period from June 1992 to August 2005, and (2) about 120 interferograms from six different tracks of C-band (wavelength $=5.63 \mathrm{~cm}$ ) ENVISAT SAR data between 2003 and August 2005, all of which are from beam mode 2 with the same imaging geometry as that for ERS-1 and ERS-2. Most of the InSAR pairs have baselines of less than $250 \mathrm{~m}$. The SAR data were collected during sub-arctic summers and autumns (mid-June to mid-October) to avoid any potential loss of coherence due to snow and ice accumulation. The images are from both descending and ascending passes. To correct the interferograms for topographic effects, we used the 1-arc-second (about 30-m posting) Shuttle Radar Topography Mission (SRTM) Digital Elevation model (DEM), which has a relative vertical accuracy of better than $10 \mathrm{~m}$ and an absolute vertical accuracy of better than $16 \mathrm{~m}$. DEM errors of this magnitude would result in no more than $6 \mathrm{~mm}$ of line-of-sight (LOS) range error in the interferograms (e.g., Massonnet and Feigl, 1998).

\subsection{InSAR time-series inversion}

Inspecting all of the ERS and ENIVSAT InSAR images, we found that coherence can be maintained reasonably well over most of the volcano in interferograms spanning 2 years or less, except in the northwest part of Augustine Island where vegetation is the thickest. Coherence decreased markedly in interferograms spanning more than 2 years. We therefore only used interferograms that span roughly 2 years or less in our analysis (Table 1). From the resulting dataset of almost 630 InSAR images, we made two key observations. First, most of the deformation observed in the interferograms occurred over the northern part of the volcano 
Table 1. C-band ERS-1, ERS-2, and ENVISAT SAR images over Augustine Volcano acquired between 1992 and August 2005 , including 184 images which were used to construct about 630 interferograms from three descending and three ascending tracks.

\begin{tabular}{|c|c|c|c|c|c|}
\hline \multicolumn{3}{|c|}{ ERS-1/ERS-2 (5 tracks) } & \multicolumn{3}{|c|}{ Envisat (6 tracks) } \\
\hline Track & SLC images & Interferograms & Track & SLC images & Interferograms \\
\hline $\begin{array}{c}229 \\
(6 / 21 / 92-8 / 31 / 05)\end{array}$ & 48 & 213 & $\begin{array}{c}229 \text { (Beam 2) } \\
(6 / 18 / 03-8 / 31 / 05)\end{array}$ & 7 & 8 \\
\hline $\begin{array}{c}501 \\
(6 / 5 / 92-8 / 15 / 05)\end{array}$ & 42 & 235 & $\begin{array}{c}501 \text { (Beam 2) } \\
(8 / 30 / 04-8 / 15 / 05)\end{array}$ & 5 & 3 \\
\hline $\begin{array}{c}164 \\
(6 / 30 / 95-8 / 27 / 05)\end{array}$ & 19 & 58 & $\begin{array}{c}164(\text { Beam 2) } \\
(7 / 19 / 03-7 / 23 / 05)\end{array}$ & 8 & 11 \\
\hline $\begin{array}{c}207 \\
(8 / 7 / 95-8 / 30 / 05)\end{array}$ & 18 & 39 & $\begin{array}{c}207(\text { Beam 2) } \\
(7 / 6 / 04-8 / 30 / 05)\end{array}$ & 5 & 6 \\
\hline \multirow[t]{2}{*}{$\begin{array}{c}436 \\
(6 / 14 / 95-8 / 11 / 05)\end{array}$} & 19 & 41 & $\begin{array}{c}436(\text { Beam 2) } \\
(6 / 17 / 04-8 / 11 / 05)\end{array}$ & 7 & 7 \\
\hline & & & $\begin{array}{c}272(\text { Beam } 2) \\
(6 / 21 / 03-7 / 30 / 05)\end{array}$ & 6 & 7 \\
\hline
\end{tabular}

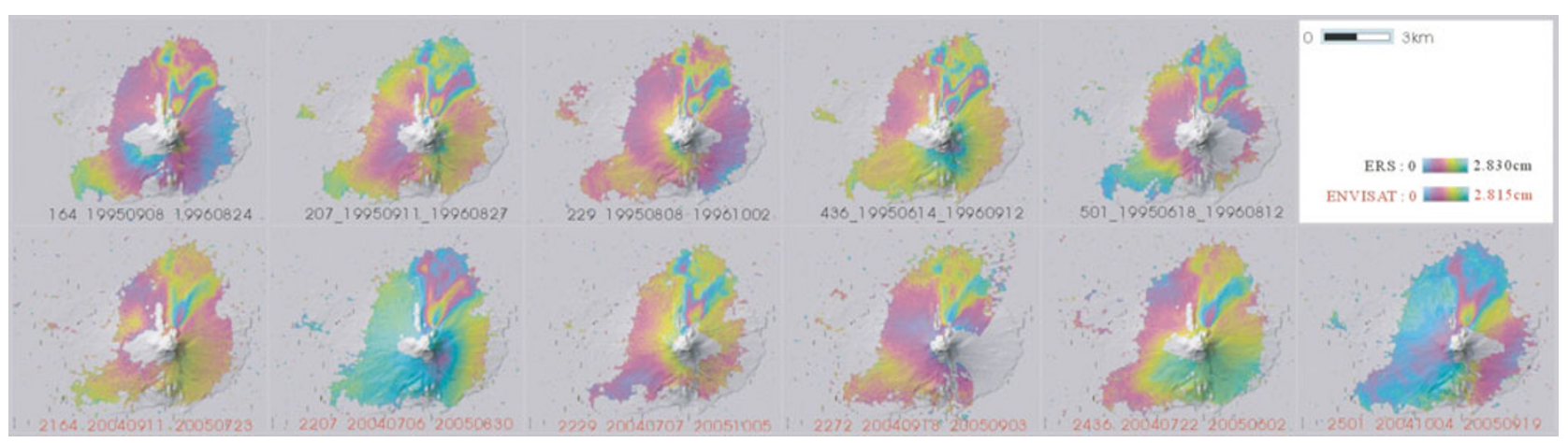

Fig. 2. Interferograms from European Remote Sensing Satellite (ERS)-1 and -2, and Environment Satellite (ENVISAT) Synthetic Aperture Radar (SAR) data from six different (ascending and descending) tracks that span about 1 year. The observed subsidence on the north-northeast flank of the volcano is due to the cooling of pyroclastic flow deposits from the 1986 eruption. Each fringe (full color cycle) represents 28.3 mm/year of line-of-sight (LOS) range change between the ground and the satellite. Areas that lack interferometric coherence are uncolored.

and was most likely associated with post-emplacement deformation of the 1986 pyroclastic flows (Lu et al., 2003; Masterlark et al., 2006). Second, the observed deformation fringes are often contaminated by atmospheric delay anomalies that can be as large as about 1 fringe $(2.83 \mathrm{~cm})$ around the volcano. Past studies have shown that atmospheric delay anomalies can be severe in the Alaskan environment (e.g., Lu et al., 2005). Consequently, it is important to reduce atmospheric contamination in the InSAR data in order to reveal any possible volcano-wide deformation.

An important question is whether or not the deformation occurred primarily in the vertical direction. Because each interferogram can only sense the deformation along the satellite's LOS direction, interferograms from three distinct imaging geometries are required to determine the threedimensional deformation field (Wright et al., 2004). Even though this is not possible for Augustine (because only two imaging geometries, ascending and descending, are available), the interferograms can still shed light on the spatial and temporal patterns of deformation. Figure 2 shows six interferograms from six independent tracks (three ascending and three descending). All of these span a time interval of about 1 year. Because these interferograms show very similar deformation patterns, we conclude that the defor- mation over the 1986 pyroclastic flow is primarily vertical. In other words, the deformation is not caused by the downslope (i.e., mostly horizontal) movement of the pyroclastic flow unit, but instead by a contraction of the deposit itself.

Next, we investigated how the subsidence over the 1986 pyroclastic flow evolved with time and whether or not volcano-wide deformation occurred during 1992-2005. To accomplish this goal, it was necessary to mitigate atmospheric artifacts in the InSAR images (e.g., Zebker et al., 1997). Using interferograms from the same tracks that span about 2 years or less and overlap in time, we employed a linear time-series inversion approach to estimate the temporal evolution of subsidence of the 1986 pyroclastic flow (Berardino et al., 2002; Usai, 2003; Schmidt and Bürgmann, 2003; Lundgren et al., 2004). Although the least-squares inversion method does not directly remove the effects of atmospheric artifacts, which are usually associated with particular epochs and are not correlated through time, it combines interferograms that overlap in time. As a result, the atmospheric artifacts are averaged, and their effects on surface deformation history are mitigated.

In this study, we adopted the singular-value decomposition (SVD) model for linear time-series inversion developed by Berardino et al. (2002) and summarized by Usai 


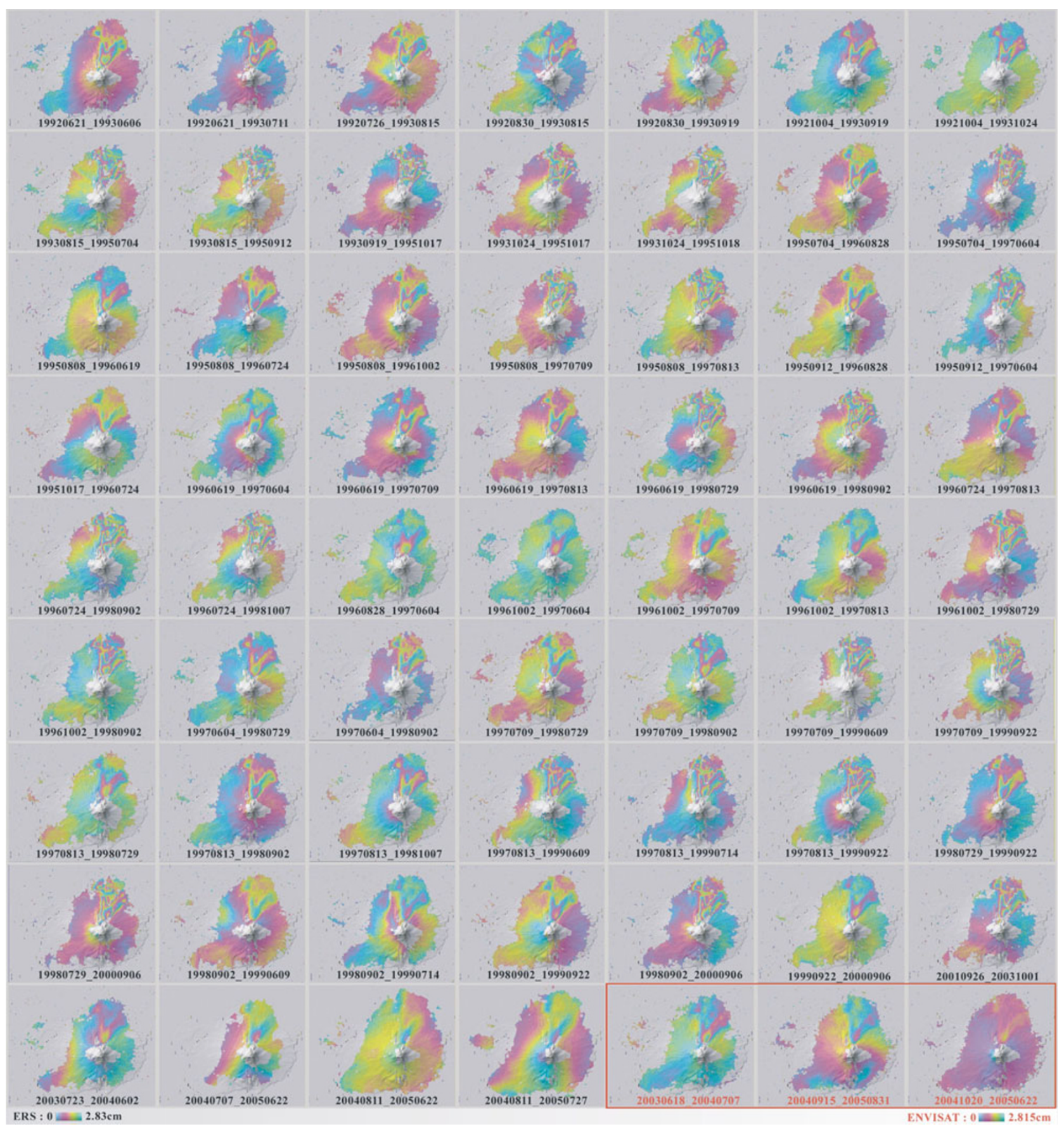

Fig. 3. Observed high-coherence interferograms from track 229 ERS-1, ERS-2, and ENVISAT images. Each fringe (full color cycle) represents $28.3 \mathrm{~mm} / \mathrm{year}$ of LOS range change between the ground and satellite. Areas that lack interferometric coherence are uncolored.

(2003). In a generic least-squares approach, it is commonly assumed that deformation velocity is constant over the time bracketed by a pair of SAR images (e.g., Usai, 2003). In the SVD method, the deformation velocity between two consecutive SAR image acquisitions is assumed to be constant. By assuming a constant deformation rate over shorter time periods, the SVD method can prevent large discontinuities in deformation estimates often produced by the generic least squares method. The overall effect is that the SVD method can provide a physically sound deformation history (Berardino et al., 2002).

The SVD method was implemented through a slight modification from the conventional linear inversion methodology described by Menke (1989):

$$
G v=\phi / \Delta t
$$

where $v$ is the unknown deformation velocity, $\phi$ is the measured deformation phase during a time interval $\Delta t$, and $G$ is the data kernel reflecting deformation velocity at individual SAR acquisition times (Berardino et al., 2002). The mean velocity at each instance can be obtained as follows:

$$
v=\left[G^{T} G\right]^{-1} G^{T} \phi / \Delta t .
$$

The time-series of deformation is obtained by incrementally integrating the deformation velocity at the times of individual SAR acquisitions. 


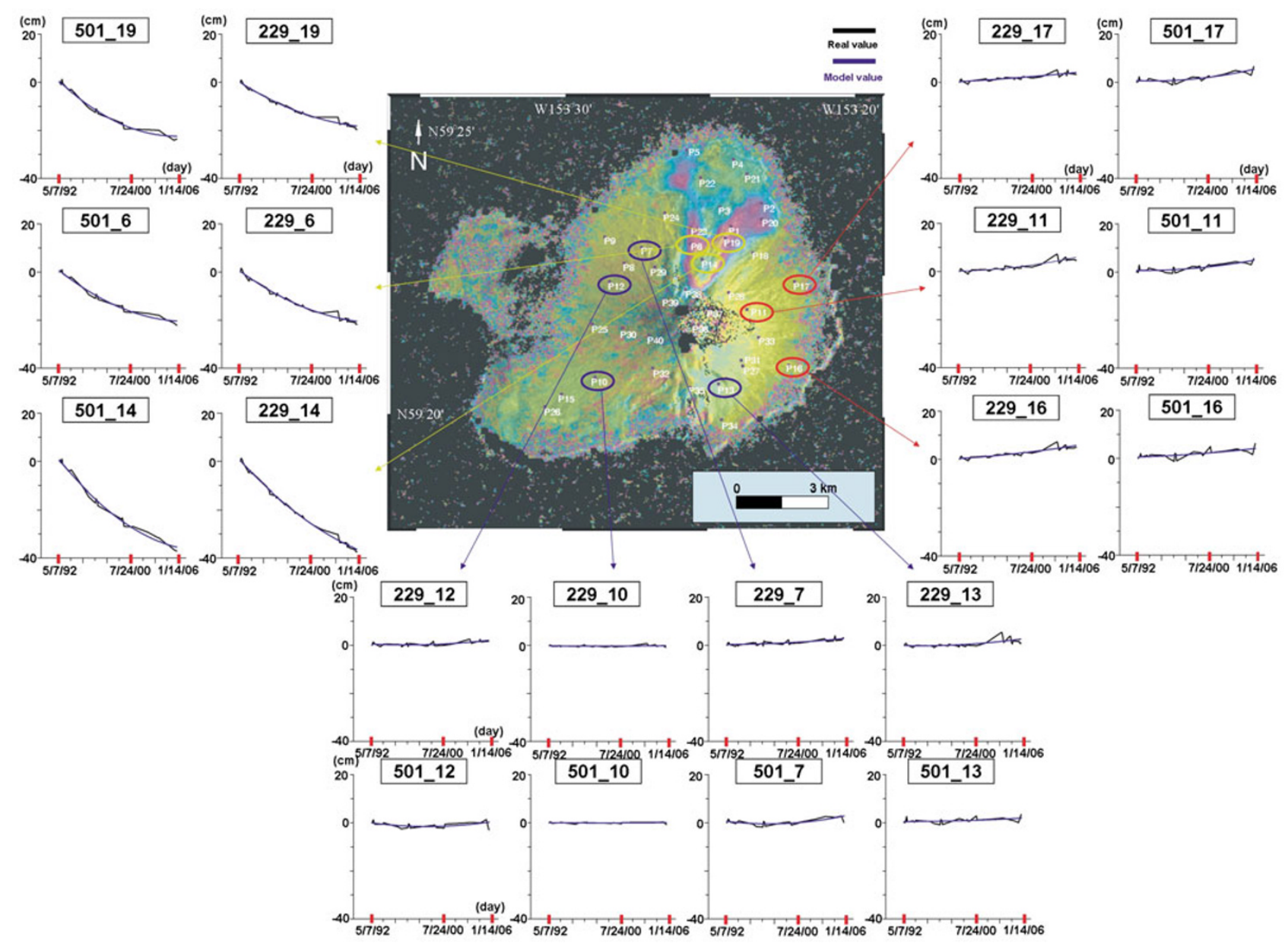

Fig. 4. Averaged InSAR image from 229 tracks created by stacking all the unwrapped 1-year interferograms between 1992 and 2005 . The time-series deformation histories for several points are shown. At each point, time-series graphs consist of deformation histories (in $\mathrm{cm}$ ) from both track 229 and track 501 interferograms during 1992 and 2005. The most significant deformation is shown by points 19, 6, and 14, which exhibit subsidence ranging from 19 to $37 \mathrm{~cm}$ during the 13-year interval. We attribute this deformation to thermal contraction of the 1986 pyroclastic flow deposits. The graphs for points 7, 11, 16, and 17 show a small amount of LOS shortening $(3-5 \mathrm{~cm})$. The abrupt range changes during 2001 and 2003 are due to a lack of coherent interferograms in the time-series inversion. Accordingly, localized atmospheric delay anomalies might still strongly influence the final results. The graphs for points 10, 12, and 13 show little deformation on the south and west flanks of Augustine Island. Blue lines are the best second-order polynomial fits to the observed deformation.

We selected high-coherence differential interferograms from tracks 229 (Fig. 3) and 501, both of which have the most ERS-1, ERS-2, and ENVISAT image acquisitions, to derive time-series deformation histories for Augustine volcano between 1992 and 2005. The time-dependent deformation is calculated by the SVD method that solves for the incremental range change between SAR scene acquisitions.

In Fig. 4, the colored background was created by averaging all the unwrapped interferograms from track 229, which spanned about 1 year between 1992 and 2005. Deformation histories estimated by the SVD method for nine selected points are also shown for both tracks 229 and 501.

\section{Discussion}

The goal of this study was to investigate the deformation of the 1986 pyroclastic flow deposits and to identify whether or not there was any volcano-wide deformation associated with magma accumulation prior to the 2005-2006 unrest and eruption. Figure 4 summarizes the main findings of our investigation. The strongest surface displacement signal was detected on the northeast flanks of the volcano.
This area corresponds to the region covered by pyroclastic flow deposits from the 1986 eruption (Fig. 1). The deformation histories at three representative points, P6, P14, and P19, show a total deformation of about $21 \mathrm{~cm}, 37 \mathrm{~cm}$, and $19 \mathrm{~cm}$ between 1992 and 2005, respectively (Fig. 4).

The deformation at these points is most likely caused by thermal contraction of 1986's pyroclastic flow deposits, and differences in subsidence magnitude among different parts of the flow are probably due to varying thicknesses of the unit (Masterlark et al., 2006). We do not attribute the persisting subsidence to the compaction of the loosely consolidated deposits because compaction-related poroelastic deformation effects occur soon after deposition (Turcotte and Schubert, 1982).

The time-series analysis suggests an exponential decrease in the subsidence rate from 1992 to 2005 . The time constants range from 5 years to 20 years, with the thickest flow having the largest time constant. Assuming the subsidence before 1992 follows the pattern determined for the 1992-2005 period, we infer that the subsidence might have reached about $25 \mathrm{~cm} /$ year in the 1986-1997 period. This 
rate is similar to the magma contraction rate at Okmok volcano, where the 1997 lava flows contracted about $12 \mathrm{~cm}$ in 88 days, 4 months after the emplacement (Lu et al., 2005).

The southwest flanks of Augustine Island show no significant deformation from 1992 through 2005 (e.g., P10, P12, and P13). However, we observed apparent range shortening over the areas just outside of the 1986 pyroclastic flows. In Fig. 4, points P7, P11, P16, and P17, showed trends of apparent volcano inflation with a maximum magnitude of about $5 \mathrm{~cm}$ between 1992 and 2005. The deformation rate is less than $4 \mathrm{~mm} /$ year over the 13 -year time span. We do not fully understand the source that brought out this apparent uplift, which may be volcanic or tectonic signal. Alternatively, this apparent deformation may be caused by the presence of atmospheric delay anomalies that survived the SVD inversion. Therefore, we cannot conclusively prove or rule out the presence of volcano-wide deformation caused by magma accumulation between 1992 and 2005. The absence of pre-eruptive deformation is not uncommon, and has also been observed in Shishaldin Volcano, Alaska (e.g., Moran et al., 2006) and Lascar Volcano in Chile (e.g., Pritchard and Simons, 2002). Future work that incorporates atmospheric delays into our SVD inversion will enhance the accuracy of InSAR measurements at Augustine.

\section{Conclusions}

We studied the surface deformation of Augustine Volcano, Alaska, using ERS-1/2 and ENVISAT data acquired between June 1992 and August 2005. Using a singular value decomposition method, we reduced deformation artifacts caused by atmospheric path delays and assembled a time-series of deformation. The 1986 pyroclastic flow deposits over the northeast flank of Augustine Volcano experienced the most significant deformation. The subsidence rate was about $1-3 \mathrm{~cm}$ per year, with a rate that decreased with time. The subsidence was most likely caused by thermal contraction of the initially hot material, and spatial heterogeneity was probably associated with differences in the thickness of the pyroclastic flow deposit. Augustine Volcano showed no significant volcano-wide uplift during 1992-2005, suggesting that if such deformation did occur, it was insignificant and may have been obscured by atmospheric delay anomalies in the InSAR results.

Acknowledgments. This study was supported by a Korea Research Foundation Grant funded by the Korean Government (MOEHRD) (KRF-2005-213-C00044), the USGS Volcano Hazards Program, and the USGS Land Remote Sensing Program. ERS-1, ERS-2, and ENVISAT images are copyright, European Space Agency (ESA), 1992-2005, and were provided by the Alaska SAR Facility (ASF) and ESA. We thank ASF and ESA User Services for providing us SAR imagery on a timely basis, and M. Poland, Q. Wang, and B. Ramachandran for reviews and comments.

\section{References}

Begét, J. E. and Z. Kowalik, Confirmation and Calibration of Computer Modeling of Tsunamis Produced by Augustine Volcano, Alaska, Sci. Tsunami Hazards, 24, 257, 2006.

Berardino, P., G. Fornaro, R. Lanari, and E. Sansosti, A New Algorithm for Surface Deformation Monitoring Based on Small Baseline Differential
SAR Interferograms, IEEE Trans. Geosci. Remote Sensing, 40, 2,3752,383, 2002.

Briole, P., D. Massonnet, and C. Delacourt, Post-eruptive deformation associated with the 1986-87 and 1989 laval flows of Etna detected by radar interferometry, Geophys. Res. Lett., 24, 37-40, 1997.

Dvorak, J. and D. Dzurisin, Volcano geodesy: The search for magma reservoirs and the formation of eruptive vents, Rev. Geophys., 35, 343384, 1997.

Dzurisin, D., A comprehensive approach to monitoring volcano deformation as a window on eruption cycle, Rev. Geophys., 41, doi:10. 1029/2001RG000107, 2003.

Lu, Z., InSAR Imaging of Volcanic Deformation Over Cloud-prone AreasAleutian Islands, Photogrammetric Eng. Remote Sensing, 73, 245-257, 2007.

Lu, Z., T. Masterlark, and D. Dzurisin, Interferometric synthetic aperture radar study of Okmok volcano, Alaska, 1992-2003: Magma supply dynamics and postemplacement lava flow deformation, J. Geophys. Res., 110, doi:10.1029/2004JB00348, 2005.

Lu, Z., Jr., C. Wicks, D. Dzurisin, J. Power, W. Thatcher, and T. Masterlark, Interferometric Synthetic Aperture Radar Studies of Alaska Volcanoes, Earth Observation Mag., 12, 2003.

Lundgren, P., F. Casu, M. Manzo, A. Pepe, P. Berardino, E. Sansosti, and R. Lanari, Gravity and magma induced spreading of Mount Etna volcano revealed by satellite radar interferometry, Geophys. Res. Lett., 31, 2004.

Massonnet, D. and K. Feigl, Radar interferometry and its application to changes in the Earth's surface, Rev. Geophys., 36,441-36,500, 1998.

Masterlark, T., Z. Lu, and R. Rykhus, Thickness distribution of a cooling pyroclastic flow deposit on Augustine Volcano, Alaska: Optimization using InSAR, FEMs, and an adaptive mesh algorithm, J. Volcanol. Geoth. Res., 150, 186-201, 2006.

Menke, W., Geophysical data analysis: Descrete inverse theory, International Geophysics Series, Academic Press, 45, 289, 1989.

Miller, T. M., R. G. McGimsey, D. H. Richter, J. R. Riehle, C. J. Nye, M. E. Yount, and J. A. Dumoulin, Catalog of the historically active volcanoes of Alaska, USGS Open-File Report, 98-582, 1998.

Moran, S. C., O. Kwoun, T. Masterlark, and Z. Lu, On the absence of InSAR-detected volcano deformation spanning the 1995-1996 and 1999 eruptions of Shishaldin Volcano, Alaska, J. Volcanol. Geoth. Res., 150, 119-131, 2006.

Pritchard, M. E. and M. Simons, A satellite geodetic survey of large-scale deformation of volcanic centres in the central Andes, Nature, 418, 167 171, 2002.

Rosen, P., S. Hensley, I. R. Joughin, F. K. Li, S. N. Madsen, E. Rodriguez, and R. M. Goldstein, Synthetic aperture radar interferometry, Proceedings IEEE, 88,333-88,380, 2000.

Schmidt, D. A. and R. Bürgmann, Time-dependent land uplift and subsidence in the Santa Clara valley, California, from a large interferometric synthetic aperture radar data set, J. Geophys. Res., 108, doi:10.1029/2002JB002267, 2003.

Stevens, N. F., G. Wadge, C. A. Williams, J. G. Morley, J.-P. Muller, J. B. Murray, and M. Upton, J. Geophys. Res., 106, 11,293-11,313, 2001.

Turcotte, D. L. and G. J. Schubert, Geodynamics: Applications of continuum physics to geological problems, John Wiley \& Sons, New York, 1982.

Usai, S., A Least Squares Database Approach for SAR Interferometric Data, IEEE Transactions on Geoscience and Remote Sensing, 41, 753760, 2003.

Waythomas, C. F. and R. B. Waitt, Preliminary Volcano-Hazard Assessment for Augustine Volcano, Alaska, U.S. Geolog. Surv., Open File Re., 98-0106, 39, 1998.

Wright, T. J., B. E. Parsons, and Z. Lu, Toward mapping surface deformation in three dimensions using InSAR, Geophys. Res. Lett., 31, L01607, doi:10.1029/2003GL018827, 2004.

Zebker, H. A., F. Amelung, and S. Jonsson, Remote Sensing of Volcano Surface and Internal Processes Using Radar Interferometry, in Remote Sensing of Active Volcanism, Geophysical Monograph, Am. Geophys. Union, 116, 179-205, 2000.

Zebker, H. A., P. A. Rosen, and S. Hensley, Atmospheric effects in interferometric synthetic aperture radar surface deformation and topographic maps, J. Geophys. Res., 102, 7547-7563, 1997.

C.-W. Lee, Z. Lu (e-mail: lu@usgs.gov), O.-I. Kwoun, and J.-S. Won 